\title{
Impact of COVID-19 on the rate of stroke cases at a tertiary hospital in Makkah, Saudi Arabia
}

\author{
Ebaa T. Samkari, MBBCh, Amal M. Alkhotani, MBBCh, Mohammed I. Siddiqui, MBBCh.
}

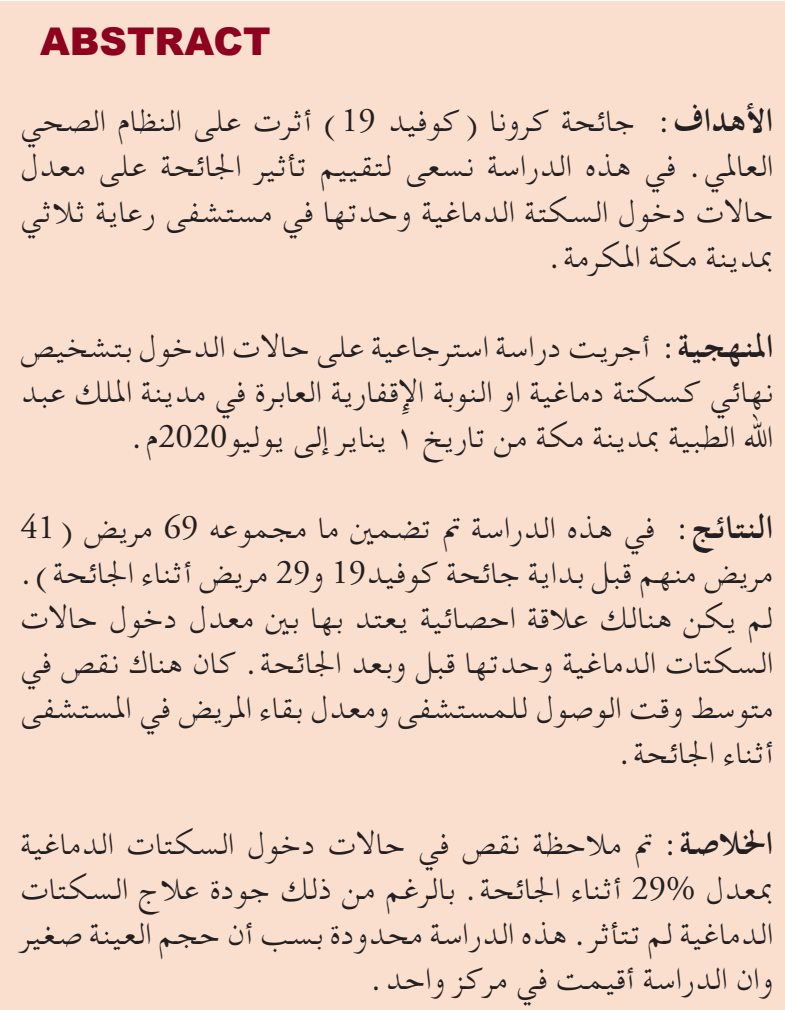

Objectives: To assess and quantify the impact COVID-19 has had thus far on ischemic stroke admission rate and severity (National Institutes of Health Stroke Scale (NIHSS) score) at a single tertiary center in Makkah, Saudi Arabia.

Methods: This is a retrospective analysis performed on admitted cases with definitive final diagnoses of transient ischemic attack (TIA) and ischemic stroke at King Abdullah Medical City in Makkah between January 1, 2020 and July 2020.

Results: Sixty-nine patients were included in our study, 41 of whom presented at our facility before the pandemic and 29 during the pandemic. No statistical significance was observed between rate of admission, stroke severity, and rate of thrombolysis before the COVID-19 pandemic and after the outbreak. We observed a reduction of mean arrival time after the pandemic began, as well as a reduction of hospital stay days.

Conclusion: A 29\% reduction of admission secondary to acute ischemic stroke was noted during the pandemic. However, COVID-19 did not affect acute stroke care at our institute. The study is limited because of its small sample size, as we assessed just one medical center.

\section{Neurosciences 2021; Vol. 26 (2): 158-162 doi: 10.17712/nsj.2021.2.20200141}

From the Department of Neurology (Samkari, Alkhotani), King Abdullah Medical City, from the Department of Community Medicine (Siddiqui), and from the Department of Medicine (Alkhotani), Umm AlQura University, Makkah, Kingdom of Saudi Arabia

Received 26th September 2020. Accepted 1st January 2020.

Address correspondence and reprint request to: Dr. Amal M Alkhotani, Department of medicine, Umm AlQura University, Makkah, Kingdom of Saudi Arabia. E-mail: Dr.amalalkhotani@hotmail.com ORCID ID: orcid.org/0000-0001-8310-1875

Stroke is the second most common cause of $\checkmark$ mortality and one of the leading causes of disability worldwide. ${ }^{1}$ In the United States, stroke occurs every 40 seconds, with a person dying every 4 minutes as a result. ${ }^{2}$ In Saudi Arabia, a recent systematic review found that there is an annual incidence of 29 strokes per 100,000 people (95\% CI: 15 to 47$).{ }^{3}$ Awada et $\mathrm{al}^{4}$ have reported that ischemic strokes accounted for $76 \%$ of these cases, of which one-third lacunar infarcts were. Most hemorrhagic strokes were intra-cerebral hemorrhages, and only $2 \%$ of all strokes were subarachnoid hemorrhages. Stroke management has different aspects, including acute intervention, investigating the cause, preventing further stroke, modifying risk factors, and preventing complications. This multifaceted approach has been associated with decreased incidence of stroke in the past 30 years in high-income countries. ${ }^{5}$ Severe acute respiratory syndrome coronavirus 2 (SARS-COV2 ) is a novel coronavirus that first appeared in Wuhan, 
China in December 2019. This virus is responsible for the COVID-19 pandemic, which has thus far seen more than 15 million cases and more than 600,000 deaths globally. ${ }^{6}$ Because of the disease's high infection rate and mortality, many governments imposed or continue to impose different protective measures to slow the transmission of the disease and to prevent cases from overwhelming health care systems. Regulations have included school shutdowns, social distancing, the compulsory wearing of masks in public places, and partial or complete local and/or national lockdowns.

The first officially reported case in Saudi Arabia was on March 2, 2020, and a partial lockdown started on March 23 of the same year. The number of cases in Makkah have increased dramatically since then, so the Ministry of Health imposed more restrictions, including a complete lockdown except for those in need of emergency medical care. ${ }^{7}$

King Abdullah Medical City is the largest and only tertiary hospital in Makkah, and the only one that can perform mechanical thrombectomy (MT). As such, it is considered to be a comprehensive stroke center, one that serves a large population in Makkah and the surrounding area. In this study, we aim to assess and quantify the impact of COVID-19 on the admission rate and severity (National Institutes of Health Stroke Scale score; NIHSS) of ischemic stroke at this single tertiary center in Makkah.

Methods. Study design and population. This is a retrospective analysis performed between January 1, 2020 and July 31, 2020 on admitted cases with definitive final diagnoses of transient ischemic attack (TIA) and ischemic stroke at King Abdullah Medical City in Makkah. Hemorrhagic strokes were excluded. We divided cases into 2 groups based on admission, with one group presenting before the start of lockdown and social distancing measures on March 23, 2020, and the other group presenting on or after this date. Evaluation of the number and severity of stroke cases were compared between the 2 groups.

Sampling technique and sample size. We used a nonprobability consecutive sampling technique, as expected cases were low in number due to low prevalence of

Disclosure. Authors have no conflict of interests, and the work was not supported or funded by any drug company. stroke rate. Only 69 patients fulfilled the definitive final diagnosis of TIA and ischemic stroke.

Data collection. Data were collected from the admission registry of the neuroscience center, and included a patient's demographic features, date of presentation, time of onset to presentation, stroke type, NIHSS, duration of admission, intensive care unit (ICU) admission and duration, and TPA and intervention. The collected data were recorded on an Excel sheet.

Statistical analysis. Data analysis was performed using SPSS (Statistical Package for the Social Sciences) version 23. Categorical variables were described using their absolute frequencies and percentages. To compare the proportion of categorical data, we used the chi square test and Fisher exact test when appropriate. Student $t$ test of independence was used to compare the numerical data. The confidence interval was set at $95 \%$ and the level of statistical significance was set at $5 \%(p<0.05)$. Difference was deemed highly significant if $p \leq 0.01$.

Ethical considerations. Ethical approval was obtained from King Abdullah Medical City's Ethics and Research Committee, and consent was waived because the study is a retrospective chart review.

Results. Table 1 shows patient demographic data. Sixty-nine patients met the inclusion criteria, with 40 presenting before and 29 presenting on or after March 23, 2020. Forty-four were male and 25 were female, and the mean ages for these groups were 61.27 and 60.86 years, respectively. However, there was no statistically significant difference of the age variable when looking at patients in the 2 groups. The majority of our cases were Saudi patients (50 individuals overall; $73 \%$ ), although this figure reduced from 30 before to 20 patients on and after March 23, but did not reach statistical significance.

The number of female admissions reduced significantly from 20 before to 5 on and after March 23, and there was a highly significant difference between pre- and post-COVID-19 admissions $(p=0.01)$. There was a reduction in total admissions of acute ischemic stroke after the lockdown in comparison with the period beforehand (29 to 40). However, this drop was not statistically significant. Table 2 shows the clinical characteristics of stroke pre- and post-March 23. There are no significant changes in the type and/or severity of stroke, mean NIHSS, rate of thrombolysis, and performance of MT. The number of ICU admissions and duration of admission were not affected by the lockdown situation. 
Discussion. The COVID-19 pandemic has had a major impact on health care systems worldwide. The disease has led to an increase in the number of acute respiratory cases presenting at hospitals and eventually ICUs, and has also affected the admissions and care of other diseases. Most countries adopted some form of curfew or lockdown, as well as preventive measures to reduce the burden of the disease. Such measures have affected the level of care patients with other acute cases have received during the pandemic. ${ }^{8,9}$ A study of 65 academic and community hospitals across the United States compared acute stroke and acute coronary syndrome (ACS) admissions from March 2020 with data from before the COVID-19 outbreak. Stroke or ACS hospitalizations in March 2020 decreased by $17.6 \%$ and $25.7 \%$ relative to March 2019 and March 2018, respectively. In March 2020, thrombolysis admissions decreased by $3.3 \%$, while MT performance increased by $18.8 \% .{ }^{10}$ These changes are likely related to the decrease in seeking medical advice for patients with acute stroke and ACS.

Another study from Brazil showed a decrease in total stroke admissions by $36.4 \%$ when compared with the same period in 2019. Significant reductions in admission were observed in relation to transient, mild, and moderate stroke, ${ }^{11}$ yet no difference was observed in admissions for severe stroke (NIHSS >8), intraparenchymal hemorrhage, and subarachnoid hemorrhage. Several other studies from different countries have demonstrated a similar effect of the COVID-19 pandemic on the admission rate for acute stroke. $^{1,8,11-21}$

Our study compared admissions before the COVID-19 outbreak (41 admissions) with those that occurred during the pandemic (29 admissions), thus noting a reduction in total admission of acute ischemic stroke between the 2 periods. We had a 29\% reduction of total acute ischemic stroke admissions during the

Table 1 - Demographic data of patients admitted at King Abdullah Hospital, Makkah.

\begin{tabular}{lcc}
\hline & $\begin{array}{c}\text { Before march 23 } \\
\mathbf{N}=40\end{array}$ & $\begin{array}{c}\text { After march 23 } \\
\mathbf{N}=\mathbf{2 9}\end{array}$ \\
\hline $\begin{array}{l}\text { Age mean(IQR) } \\
\text { Gender }\end{array}$ & $61.27(23-85)$ \\
Male & & \\
Female & $21(51)$ & $23(79)$ \\
Nationality & $20(49)$ & \\
saudi & & \\
Non Saudi & $30(73)$ & $20(68)$ \\
\hline
\end{tabular}

pandemic, although this was not statistically significant because of the small sample size in the current study. There were no significant differences in the admission rate for TIA, or minor or major stroke between the preand post-COVID-19 periods. As a tertiary care center in Makkah, our facility's emergency room is restricted to eligible patients and those referred from other hospitals in the region. Our data show a reduction in such referrals

Table 2 - Clinical characteristic of stroke patients. mean \pm SD.

\begin{tabular}{|c|c|c|}
\hline \multirow[t]{2}{*}{ Characteristic } & $\begin{array}{c}\text { Before march } \\
23 \\
n=41\end{array}$ & $\begin{array}{c}\text { After } \\
\text { march } 23 \\
n=29\end{array}$ \\
\hline & \multicolumn{2}{|c|}{$\mathbf{n}(\%)$} \\
\hline \multicolumn{3}{|l|}{ Type of stroke $N$} \\
\hline TIA & 3 & 1 \\
\hline minor stroke NIHSS $<4$ & 13 & 8 \\
\hline moderate strokes NIHSS 5-8 & 7 & 8 \\
\hline severe stroke NIHSS>8 & 18 & 11 \\
\hline Likelihood ratio & 1.558 & \\
\hline$P$-value & 0.669 & \\
\hline NIHSS & $9.1 \pm 7.7$ & $9.0 \pm 6.9$ \\
\hline$P$-value & 0.953 & \\
\hline Stroke onset before $4.5 \mathrm{hrs}$ & $12(29)$ & $10(34.5)$ \\
\hline Likelihood ratio & 0.0317 & \\
\hline $\mathrm{P}$-value & 0.574 & \\
\hline Hours from onset to arrival & $21.9 \pm 38$ & $8.0 \pm 8.2$ \\
\hline$P$-value & 0.032 & \\
\hline \multicolumn{3}{|l|}{ Source } \\
\hline ER & 29 & 24 \\
\hline Referral N & 12 & 4 \\
\hline Likelihood ratio & 2.194 & \\
\hline$P$-value & 0.139 & \\
\hline \multicolumn{3}{|l|}{ Thrombolysis $N$} \\
\hline Yes & 34 & 21 \\
\hline no & 7 & 7 \\
\hline Likelihood & 0.036 & \\
\hline$P$-value & 0.85 & \\
\hline Admission duration/days & $14.8 \pm 26$ & $9.7 \pm 14.9$ \\
\hline P-value & 0.311 & \\
\hline \multicolumn{3}{|l|}{ ICU admission $N$} \\
\hline Yes & 18 & 12 \\
\hline No & 23 & 16 \\
\hline Likelihood & 0.007 & \\
\hline$P$-value & 0.931 & \\
\hline ICU admissions duration /days & $11.1 \pm 14$ & $9.7 \pm 14.8$ \\
\hline$P$-value & 0.266 & \\
\hline Death $N$ & 3 & 3 \\
\hline Likelihood ratio & 0.238 & \\
\hline$P$-value & 0.626 & \\
\hline
\end{tabular}


for acute stroke (from 12 to 4), which indicates the reduction of acute stroke cases seen in other hospitals that have more availability to treat acutely sick patients. The results might have been different if the study was carried out at other hospitals more directly affected by the COVID-19 pandemic.

In our study, there was no significant change in the number of cases that received thrombolysis or MT. An interesting finding was that prior to the COVID-19 pandemic, the mean duration of symptoms before arrival at hospital was 21.9 hours, whereas during the pandemic it had reduced to 8 hours $(p=0.032)$. This may be related to more utilization of Red Crescent during the curfew time. During this period, patients required a permit to leave their homes, which prompted more utilization of the emergency services. Another possibility is the wider use of telemedicine and the availability of a hot line to answer patients' queries, which led to solutions without requiring individuals to attend medical facilities in order to gain medical advice for acute stroke patients. Our results deviate from those of Böjti et $\mathrm{al},{ }^{12}$ who observed a significant delay in the arrival time of patients suffering from acute stroke. In their study, they observed a $13 \%$ increase of patients arriving after 24 hours. ${ }^{12}$ This effect was also seen in a study conducted in Hong Kong, which showed a prolongation of time of onset to emergency room arrival. ${ }^{22}$ Another interesting yet not statistically significant point is the duration of admissions, which we observed to be 5 days shorter during the pandemic. This is likely because the chronic case load lessened during this time, facilitating the work up for admitted cases and resulting in quicker access to radiology and cardiac investigations.

COVID-19 has not only affected the rate of acute stroke admission but also the pathway and the chain of management of acute stroke. A study from Italy during the nation's lockdown showed a significant increase in onset-to-door time (median=387 vs $161 \mathrm{~min}, p=0.001$ ), with thrombolysis ( 7 vs $13, p=0.033$ ) and a significant increase in door-to-groin time noted (median $=120$ vs $93 \mathrm{~min}, p=0.048) .{ }^{23}$ Another study from France showed $21 \%$ reduction of MT since the start of the pandemic (0.79; [95\%CI, 0.76-0.82]; $p<0.001$ ), with significant increase observed between imaging-to-groin time (mean 144.9 \pm SD 86.8 mins versus $126.2 \pm 70.9 ; p<0.001$ in 2019). ${ }^{24}$ A study from New York City found longer median door-to-head CT times (16 vs $12 \mathrm{~min} ; p=0.05$ ), as well as longer door-to-groin puncture times (79.5 vs. $71 \mathrm{~min}, p=0.06$ ). However, time to thrombolysis (36 vs $35 \mathrm{~min}$; $p=0.83$ ), door-to-reperfusion times (103 vs 97 min, $p=0.18)$, and defect-free care $(95.2 \%$ vs $94.7 \%$; $p=0.84$ ) were similar in the before and during pandemic groups. ${ }^{25}$ We did not look at this particular point in our study.

Study limitations. The main limitation of our study is its small sample size, as the research took place at one medical facility, King Abdullah Medical City. In order to understand better the effects of the COVID-19 pandemic on stroke admission, it would be beneficial to recruit more centers and evaluate larger sample data in future studies.

In conclusion, our study showed a reduction of stroke admission during the pandemic. However, we did not observe any major impact of COVID-19 on the care of active acute stroke cases. Of interest, patients arrived at the emergency room more rapidly after the onset of acute stroke during the pandemic, and admission duration was shorter.

\section{References}

1. Hoyer C, Ebert A, Huttner HB, Puetz V, Kallmünzer B, Barlinn K, et al. Acute Stroke in Times of the COVID-19 Pandemic: A Multicenter Study. Stroke 2020; 51: 2224-2227.

2. Benjamin EJ, Blaha MJ, Chiuve SE, Cushman M, Das SR, Deo R, et al. Heart Disease and Stroke Statistics-2017 Update: A Report From the American Heart Association. Circulation 2017; 135: e146-e603.

3. Alqahtani BA, Alenazi AM, Hoover JC, Alshehri MM, Alghamdi MS, Osailan AM, et al. Incidence of stroke among Saudi population: a systematic review and meta-analysis. Neurol Sci 2020.

4. Awada A, al Rajeh S. The Saudi Stroke Data Bank. Analysis of the first 1000 cases. Acta Neurol Scand 1999; 100: 265-269.

5. Katan M, Luft A. Global Burden of Stroke. Semin Neurol 2018; 38: 208-211.

6. Dong E, Du H, Gardner L. An interactive web-based dashboard to track COVID-19 in real time. Lancet Infect Dis 2020; 20: 533-534.

7. Agency, SP. 2020; Available from: https://www.spa.gov. sa/2051223.

8. Bersano A, Kraemer M, Touzé E, Weber R, Alamowitch S, Sibon I, et al. Stroke care during the COVID-19 pandemic: experience from three large European countries. Eur J Neurol 2020.

9. Schwarz V, Mahfoud F, Lauder L, Reith W, Behnke S, Smola S, et al. Decline of emergency admissions for cardiovascular and cerebrovascular events after the outbreak of COVID-19. Clin Res Cardiol 2020: 1-7.

10. de Havenon A, Ney J, Callaghan B, Delic A, Hohmann S, Shippey E, et al. A Rapid Decrease in Stroke, Acute Coronary Syndrome, and Corresponding Interventions at 65 United States Hospitals Following Emergence of COVID-19. medRxiv 2020.

11. Diegoli H, Magalhães PSC, Martins SCO, Moro CHC, França PHC, Safanelli J, et al. Decrease in Hospital Admissions for Transient Ischemic Attack, Mild, and Moderate Stroke During the COVID-19 Era. Stroke 2020; 51: 2315-2321. 
12. Böjti PP, Stang R, Gunda B, Sipos I, Bereczki D. [Effects of COVID-19 pandemic on acute ischemic stroke care. A singlecentre retrospective analysis of medical collateral damage]. Orv Hetil 2020; 161: 1395-1399. Hu

13. Desai SM, Guyette FX, Martin-Gill C, Jadhav AP. Collateral damage - Impact of a pandemic on stroke emergency services. J Stroke Cerebrovasc Dis 2020; 29: 104988.

14. Hsiao J, Sayles E, Antzoulatos E, Stanton RJ, Sucharew H, Broderick JP, et al. Effect of COVID-19 on Emergent Stroke Care: A Regional Experience. Stroke 2020; 51: e2111-e2114.

15. Jasne AS, Chojecka P, Maran I, Mageid R, Eldokmak M, Zhang Q, et al. Stroke Code Presentations, Interventions, and Outcomes Before and During the COVID-19 Pandemic. Stroke 2020; 51: 2664-2673.

16. Kristoffersen ES, Jahr SH, Thommessen B, Rønning OM. Effect of COVID-19 pandemic on stroke admission rates in a Norwegian population. Acta Neurol Scand 2020.

17. Naccarato M, Scali I, Olivo S, Ajčević M, Buoite Stella A, Furlanis G, et al. Has COVID-19 played an unexpected "stroke" on the chain of survival? J Neurol Sci 2020; 414: 116889.

18. Rinkel LA, Prick JCM, Slot RER, Sombroek NMA, Burggraaff J, Groot AE, et al. Impact of the COVID-19 outbreak on acute stroke care. J Neurol 2020: 1-6.
19. Sharma M, Lioutas VA, Madsen T, Clark J, O’Sullivan J, Elkind MSV, et al. Decline in stroke alerts and hospitalisations during the COVID-19 pandemic. Stroke Vasc Neurol 2020.

20. Siegler JE, Heslin ME, Thau L, Smith A, Jovin TG. Falling stroke rates during COVID-19 pandemic at a comprehensive stroke center. J Stroke Cerebrovasc Dis 2020; 29: 104953.

21. Uchino K, Kolikonda MK, Brown D, Kovi S, Collins D, Khawaja Z, et al. Decline in Stroke Presentations During COVID-19 Surge. Stroke 2020; 51: 2544-2547.

22. Teo KC, Leung WCY, Wong YK, Liu RKC, Chan AHY, Choi OMY, et al. Delays in Stroke Onset to Hospital Arrival Time During COVID-19. Stroke 2020; 51: 2228-2231.

23. Frisullo G, Brunetti V, Di Iorio R, Broccolini A, Caliandro P, Monforte M, et al. Effect of lockdown on the management of ischemic stroke: an Italian experience from a COVID hospital. Neurol Sci. 2020; 41: 2309-2313.

24. Kerleroux B, Fabacher T, Bricout N, Moïse M, Testud B, Vingadassalom S, et al. Mechanical Thrombectomy for Acute Ischemic Stroke Amid the COVID-19 Outbreak: Decreased Activity, and Increased Care Delays. Stroke 2020; 51: 2012-2017.

25. Agarwal S, Scher E, Rossan-Raghunath N, Marolia D, Butnar $\mathrm{M}$, Torres J, et al. Acute stroke care in a New York City comprehensive stroke center during the COVID-19 pandemic. J Stroke Cerebrovasc Dis 2020; 29: 105068.

\section{Ethical Consent}

All manuscripts reporting the results of experimental investigations involving human subjects should include a statement confirming that informed consent was obtained from each subject or subject's guardian, after receiving approval of the experimental protocol by a local human ethics committee, or institutional review board. When reporting experiments on animals, authors should indicate whether the institutional and national guide for the care and use of laboratory animals was followed. 